\title{
Conhecimento de graduandos em Odontologia sobre a Harmonização Orofacial
}

\author{
Ana Luísa Rezende Machado*; Ricardo Henrique Alves da Silva**
}

* Mestranda, Departamento de Patologia e Medicina Legal, Faculdade de Medicina de Ribeirão Preto, Universidade de São Paulo

** Professor Doutor, Faculdade de Odontologia de Ribeirão Preto, Universidade de São Paulo

Recebido em 18/07/2019. Aprovado em 18/04/2020.

\begin{abstract}
RESUMO
A procura por tratamentos estéticos e rejuvenescedores se apresenta de forma crescente na sociedade, circunstância que também se evidencia na Odontologia, na qual muitos profissionais objetivam, majoritariamente, o realce da beleza do paciente. Nesse quadro, muitos cirurgiões-dentistas têm realizado procedimentos com o objetivo de harmonizar dentes, lábios e face como um todo, o que precisa ser analisado a luz da legislação vigente, considerando também as normas administrativas e resoluções pertinentes. Dessa forma, o presente estudo objetivou averiguar o conhecimento de graduandos em Odontologia, do primeiro e do último semestre, por meio de um questionário abordando os aspectos éticos e legais de procedimentos que integram a Harmonização Orofacial, assim como as fontes informações sobre o assunto. Foi possível observar que, no primeiro semestre do curso, grande parte das respostas abrange a permissibilidade dos procedimentos, fato que difere das respostas dos estudantes do último semestre, os quais consideram, predominantemente, tais procedimentos como não pertinentes à área de competência do cirurgião-dentista. Isto posto, fica evidenciada a importância do ensino frente à formação de um perfil crítico e reflexivo durante a graduação, visto a divergência entre o entendimento dos participantes do primeiro e último do semestre quanto a permissibilidade dos procedimentos.

Descritores: Ética Odontológica. Estética. Legislação Odontológica. Odontologia Legal.
\end{abstract}




\section{INTRODUÇÃO}

A demanda por estética e rejuvenescimento vem crescendo progressivamente na sociedade, assim como ocorre com a oferta de produtos, técnicas e equipamentos que prometem realçar a beleza e minimizar os sinais de envelhecimento, tornando os procedimentos cada vez mais complexos, por serem produtos do desenvolvimento técnico-científico ${ }^{1-3}$.

Muitos profissionais da área odontológica possuem a estética e o rejuvenescimento como seus principais objetivos, os quais não abrangem apenas o terço inferior da face, como os dentes e estruturas de suporte, visto que o novo conceito da denominada Harmonização Orofacial pretende combinar dentes, lábios e face em um equilíbrio estético e funcional integrado ${ }^{1,4,5}$.

Nessa seara, inúmeros cursos de capacitação estão propagando técnicas com uma perspectiva simplista dos procedimentos com poucas horas de aprendizado. Dentre as técnicas e procedimentos ensinados nos referidos cursos citase, entre outros, a realização da bichectomia, o uso de toxina botulínica e do ácido hialurônico ${ }^{1,6}$.

Contudo, a legislação e as resoluções vigentes ainda são deficientes quanto a esse novo campo de atuação, existindo desacordo entre profissionais de categorias distintas sobre os limites de atuação, o que traz mais incertezas e controvérsias sobre a permissibilidade dos procedimentos para a Odontologia ${ }^{2,7}$.

Adicionalmente, $\mathrm{o}$ aspecto técnico se encontra, frequentemente, desvinculado dos princípios éticos e legais, fato que contribui para o desconhecimento e desinteresse da classe sobre os campos de atuação e a legislação pertinente ${ }^{8-10}$.

Tendo em vista tal conjuntura, se faz necessária a maior abrangência do ensino da Ética e Bioética, não apenas apresentando os artigos do Código de Ética Odontológica, mas abordando também a importância da educação continuada, da comunicação com o paciente e das frequentes questões conflituosas que envolvem a prática diária do cirurgião-dentista ${ }^{9}$.

A Odontologia Legal, nesse sentido, possui papel fundamental para a conscientização da classe, visto que aborda conteúdos éticos, legais, deontológicos e diceológicos, contribuindo, assim, para uma formação generalista, humanista, crítica e reflexiva do estudante de graduação, fugindo do ensino mecanicista e mercantilista ${ }^{9-11}$.

$\mathrm{O}$ presente estudo objetivou averiguar o conhecimento de graduandos em Odontologia, do primeiro e do último semestre, sobre a atual permissão e abrangência de diferentes procedimentos realizados na Harmonização Orofacial, assim como as fontes informações sobre o assunto.

\section{METODOLOGIA}

$\mathrm{O}$ projeto foi submetido à apreciação pelo Comitê de Ética em Pesquisa com Seres Humanos, a fim de cumprir todos os requisitos exigidos pela Resolução 466/12 12 , sendo aprovado sob CAAE 98630118.7.0000.5419.

Para a realização do presente estudo, foram selecionados de maneira aleatória 40 estudantes do primeiro e do último semestre do curso de graduação em Odontologia da Faculdade de Odontologia de Ribeirão Preto da Universidade de São Paulo.

Foi realizada a explicação da pesquisa e leitura do Termo de Consentimento Livre e Esclarecido (TCLE). Uma vez aceito o convite, foi entregue um questionário anônimo e autoaplicável, com um total de dez questões com possível resposta "sim", "não" e "não sei" a respeito de procedimentos em harmonização orofacial, conforme apresentado na figura 1.

As respostas foram tabuladas em uma planilha Excel (Microsoft, Redmond, Washington, Estados Unidos) e os resultados analisados por meio de estatísticas descritivas. 

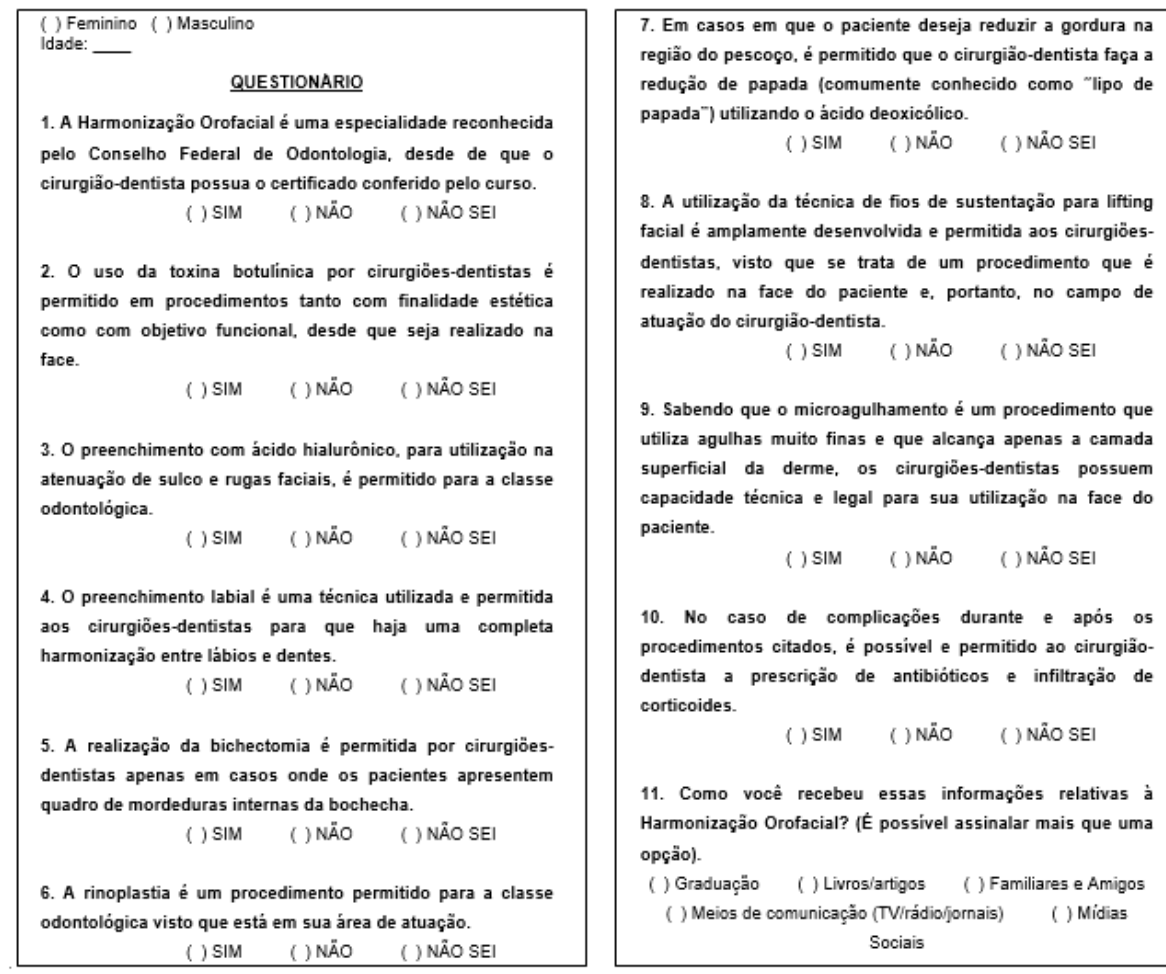

Figura 1. Questionário aplicado aos estudantes

\section{RESULTADOS}

A amostra de estudantes do primeiro semestre foi composta por 27 indivíduos do sexo feminino e 13 do sexo masculino, com idade média de 19,8 anos. Os mesmos apresentaram uma média geral de respostas com a opção "não sei" de $38 \%$, sendo a pergunta que apresentou a maior média com essa opção foi sobre a permissão de realização do procedimento denominado "lifting facial" por cirurgiõesdentistas.

No gráfico 1 é possível observar as respostas dos estudantes do primeiro semestre para cada questão. A maior média de respostas com a opção "não" $(60 \%)$ foi sobre a permissibilidade de realização do procedimento de rinoplastia pelos cirurgiões-dentistas, seguida pela permissibilidade de realização da bichectomia apenas em casos de mordeduras internas da bochecha, com $45 \%$. Já a opção "sim" foi a mais frequente sobre prescrição de antibióticos e infiltração de corticóides, com $77,5 \%$.

Quanto aos graduandos do último semestre, a amostra foi composta por 23 indivíduos do sexo feminino e 17 do sexo masculino, com idade média de 23,75 anos. Os mesmos apresentaram uma média de respostas de $20 \%$ para a opção "não sei”, sendo a pergunta que apresentou a maior média com essa opção foi sobre a prescrição de antibióticos e infiltração de corticoides por cirurgiões-dentistas após complicações de procedimentos em harmonização orofacial.

A maior média de respostas com a opção "não" (95\%) foi sobre a permissibilidade de realização do procedimento de rinoplastia. Para a opção "sim", foi observada maior média na questão que envolvia o procedimento de bichectomia apenas em casos de mordedura interna da bochecha (83\%) (gráfico 2). 


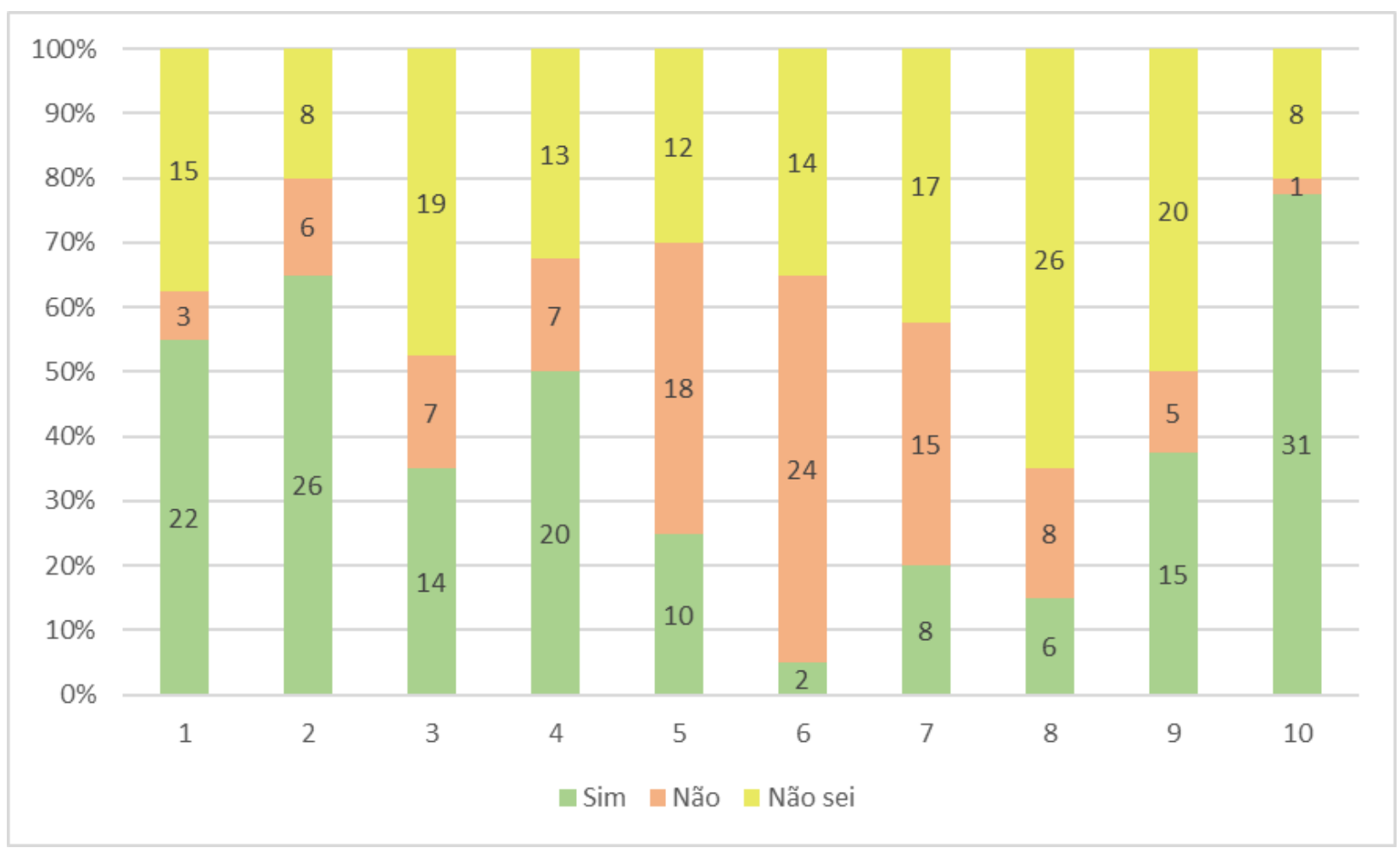

Gráfico 1. Distribuição das respostas dos estudantes do primeiro semestre para as 10 perguntas sobre a permissibilidade de procedimentos

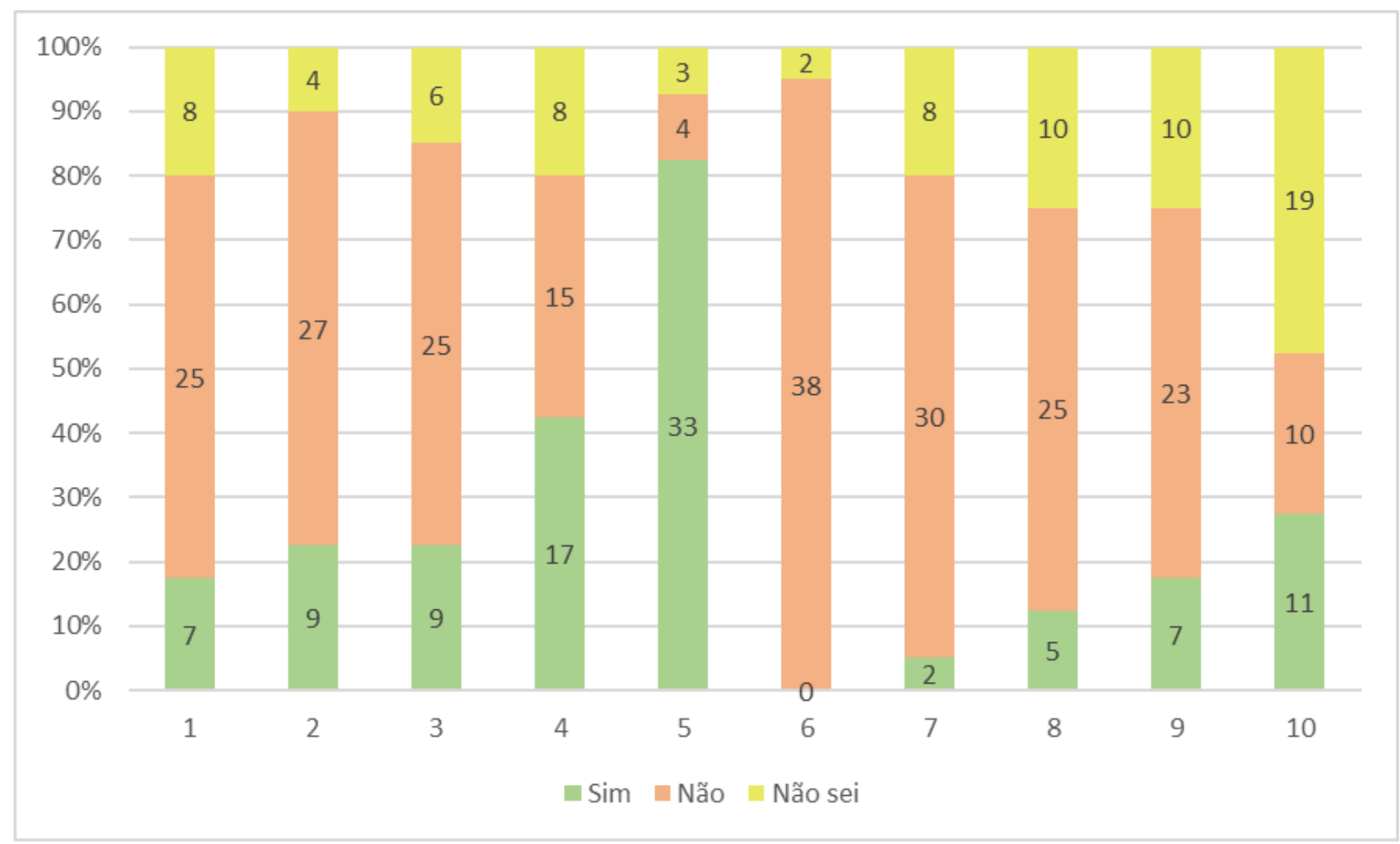

Gráfico 2. Distribuição das respostas dos estudantes do décimo semestre para as 10 perguntas sobre a permissibilidade de procedimentos 
Sobre as opções de fontes de informações quanto às questões de Harmonização Orofacial, 23 estudantes do primeiro semestre selecionaram as mídias sociais e 21 selecionaram familiares e amigos, sendo as duas opções com maiores índices de escolha.

Já os graduandos do último período selecionaram a graduação e 23 selecionaram as mídias sociais, sendo as duas opções com maiores índices de escolha (gráfico 3).

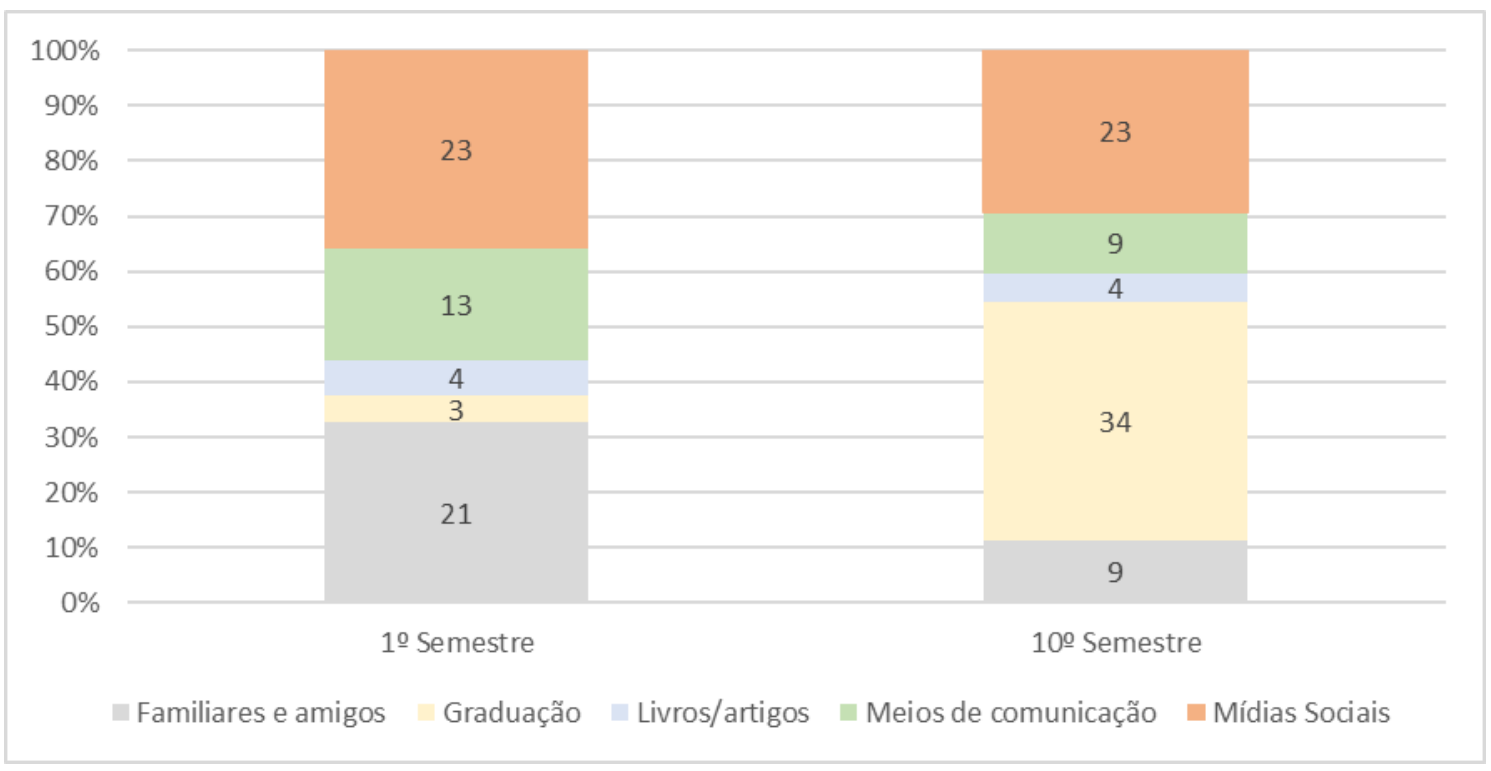

Gráfico 3. Distribuição da fonte de informações sobre a Harmonização Orofacial Porcentagem entre os estudantes do primeiro e do décimo semestre (respostas múltiplas).

\section{DISCUSSÃO}

Tendo em vista o acelerado desenvolvimento de tecnologias e a grande expressão das mídias sociais na esfera odontológica, o Conselho Federal de Odontologia (CFO) tem publicado inúmeras resoluções a fim de regulamentar a realização de novos procedimentos, principalmente quando se refere à nova especialidade denominada de Harmonização Orofacial ${ }^{13}$.

A primeira resolução que contemplou os limites de atuação em relação às cirurgias estéticas, entre elas a bichectomia (procedimento que envolve tal especialidade), foi a Resolução CFO-100/2010 ${ }^{14}$, a qual foi elaborada conjuntamente entre os conselhos federais de
Odontologia e Medicina. Esta resolução estabelece que é de competência exclusiva do médico a prática de cirurgias exclusivamente estéticas, sendo de competência do cirurgiãodentista apenas cirurgias estéticas funcionais do aparelho mastigatório ${ }^{14}$.

Já a primeira resolução que contemplou o preenchimento com ácido hialurônico e a utilização da toxina botulínica em Odontologia, foi a Resolução CFO-112/2011 ${ }^{15}$, a qual proibiu o uso do ácido hialurônico até que houvesse evidências científicas mais robustas. $\mathrm{O}$ uso da toxina botulínica em procedimentos odontológicos restringiu-se apenas para fins terapêuticos, não sendo permitido para fins estéticos, conforme os seguintes artigos da 
resolução supracitada ${ }^{15}$ :

“Art. 1". Proibir o uso do ácido hialurônico em procedimentos odontológicos até que se tenha melhores comprovações científicas e reconhecimento da sua utilização na área odontológica.

Art. $2^{o}$. Proibir o uso da toxina botulínica para fins exclusivamente estéticos e permitir para uso terapêtico em procedimentos odontológicos."

Em 27 de março de 2014, o Conselho Federal de Odontologia publicou a Resolução $145 / 2014^{16}$, na qual permitiu o uso do ácido hialurônico com devida comprovação científica. Dessa forma, alterou-se o artigo $1^{\circ}$ e $2^{\circ}$ da Resolução CFO-112/2011 ${ }^{15}$ com a seguinte redação:

"Art. 1". Permitir o uso do ácido hialurônico em procedimentos odontológicos, com reconhecida comprovação científica.

Art. $2^{\circ}$. O uso da toxina botulínica será permitido para uso terapêutico em procedimentos odontológicos e vedado, exclusivamente, para utilização em procedimentos estéticos."

No mesmo ano, a Resolução $146 / 2014^{17}$ foi publicada para alterar o segundo artigo da Resolução $145 / 2014^{16}$ e assim, permitir o uso da toxina botulínica para procedimentos odontológicos e vedar para procedimentos não odontológicos.

Do mesmo modo, em 6 de setembro de 2016, o Conselho Federal de Odontologia publicou a Resolução 176/2016 ${ }^{18}$ revogando as resoluções anteriores baseado no artigo $6^{\circ}$ da Lei 5.081 de $1966^{19}$, onde:

"Art. $6^{\circ}$ Compete ao cirurgião-dentista:

I - praticar todos os atos pertinentes a Odontologia, decorrentes de conhecimentos adquiridos em curso regular ou em cursos de pós-graduação;
II - prescrever e aplicar especialidades farmacêuticas de uso interno e externo, indicadas em Odontologia;"

Assim, o Conselho Federal de Odontologia autorizou a utilização de toxina botulínica e preenchedores faciais pelo cirurgião-dentista, para fins terapêuticos e/ou funcionais, desde que não extrapole sua área de atuação: superiormente ao osso hioide até o ponto násio e anteriormente ao tragus, podendo incluir o terço superior da face em procedimentos não cirúrgicos ${ }^{18}$.

Entretanto, esta última resolução entra em conflito com a Consolidação das Normas para Procedimentos nos Conselhos de Odontologia ${ }^{20}$, visto que a mesma estabelece limites quanto à finalidade dos procedimentos, autorizando apenas para fins funcionais e, quanto à área de atuação, não permite a atuação no terço superior da face, visto que estabelece o ponto násio como limite superior? ${ }^{7}$.

Isto posto, a Associação Médica Brasileira e a Sociedade Brasileira de Cirurgia Plástica, ajuizaram uma ação pública, objetivando a suspensão da Resolução 176/2016 ${ }^{18}$ visto que os procedimentos estéticos são invasivos e assim, exclusivos da classe médica. Em dezembro de 2017, o juiz responsável pelo processo deferiu o pedido de tutela antecipada e a resolução foi suspensa $^{21}$. Contudo, em novembro de 2018, a mesma resolução volta a ter validade pela extinção do processo sem apreciação do mérito ${ }^{22}$. Já no início de 2019, o CFO publicou a Resolução 198/2019 13 reconhecendo a Harmonização Orofacial como especialidade odontológica, fundamentando-a na existência de cursos de pós-graduação em instituições de ensino superior. Além disso, elencou diversos procedimentos pertencentes à especialidade, como o uso da toxina botulínica, dos preenchedores faciais, de biomateriais indutores percutâneos de colágeno, fios orofaciais, a realização de lipoplastia facial, bichectomia e 
correção dos lábios.

É fundamental ressaltar que a referida resolução não altera ou suspende as resoluções anteriores, havendo assim, uma nova incompatibilidade com a Consolidação das Normas para Procedimentos nos Conselhos de Odontologia ${ }^{20}$, assim como com a Resolução $100 / 2010^{14}$, a qual estabelece como competência do cirurgião-dentista apenas as cirurgias estéticas funcionais do aparelho mastigatório.

À vista disso, grande parte dos estudantes do primeiro semestre considera permitido o uso da toxina botulínica, a realização do preenchimento labial e bichectomia em casos funcionais e/ou estéticos. Além disso, a porcentagem de respostas "não sei" se apresentou elevada nas questões sobre a permissibilidade do procedimento de "lipo de papada", lifting e microagulhamento facial. Contrariamente, grande parte dos graduandos do último semestre considera esses procedimentos como proibidos aos cirurgiões-dentistas. Já para as respostas "não sei", se destaca apenas a questão que envolve a permissibilidade da prescrição de antibióticos e infiltração de corticoides após complicações de procedimentos em Harmonização Orofacial.

Os estudantes que atualmente frequentam as universidades apresentam-se como uma geração conectada às tendências globais, não adotando o ensino tradicional centrado nos professores, mas sim construindo o conhecimento de maneira ativa e dinâmica, o qual se torna grande aliado às tecnologias de informação e comunicação para a melhorar sua motivação e aprendizagem ${ }^{23}$.

A faixa populacional que mais faz uso das ferramentas de comunicação, como as redes sociais, está entre os 18 e 25 anos, a qual está predominantemente cursando o ensino superior. Dessa forma, estes meios de comunicação possuem grande influência na sociedade e na educação, resultando em um processo de ensino e aprendizagem cada vez mais complexo e desafiador ${ }^{24}$.

O mesmo ocorre na área odontológica, onde os estudantes e profissionais utilizam as redes sociais para divulgação de seus trabalhos, os quais incluem, muitas vezes, os procedimentos realizados, imagens de antes e depois, os casos clínicos e os exames complementares, resultando em mercantilização e desvalorização da profissão ${ }^{25-27}$.

Diante disso, fica clara a crescente cultura do imediatismo na Odontologia, a qual visa o lucro por meio do exercício da profissão predominantemente mercantil ${ }^{28}$. Henry et al. ${ }^{26}$ constataram que $87 \%$ dos cirurgiões-dentistas participantes do estudo possuem algum tipo de website e $51 \%$ utilizam as redes sociais em suas práticas profissionais. Similarmente, Martorell et $a l .{ }^{25}$ verificaram que $56,1 \%$ das imagens de pacientes e procedimentos odontológicos publicadas em redes sociais estão associadas aos perfis de cirurgiões-dentistas ou de clínicas/consultórios, seguido pelos perfis de estudantes de Odontologia (28,5\%) e depois pelos perfis dos próprios pacientes com apenas $6,5 \%$ das publicações.

No presente estudo, é possível observar a potencial influência das redes sociais sobre os graduandos, visto que grande parcela dos estudantes do primeiro semestre da graduação em Odontologia escolheram a opção "mídias sociais" como fonte de informações sobre os procedimentos da Harmonização Orofacial, totalizando aproximadamente $57 \% \quad(n=23)$. Paralelamente, 34 graduandos do último semestre escolheram a opção "graduação" e 23 a opção "mídias sociais", demonstrando que, apesar da influência que esta última possui sobre o aprendizado, a graduação possui papel fundamental na sua formação.

Neste contexto, as disciplinas relacionadas 
à Odontologia Legal são indispensáveis, dado que as mesmas objetivam desenvolver um perfil reflexivo, crítico e humanista dos acadêmicos, não apenas voltado para a deontologia, mas também com o desenvolvimento ético e moral, visando os riscos e possíveis consequências existentes em seu futuro profissional, pacientes e sociedade $^{9,25}$.

Dessa forma, dois pontos ficam claros. Primeiramente, a importância do ensino da Odontologia Legal durante a graduação para que os estudantes conheçam as legislações que cercam a profissão, e assim, saibam o que é permitido ou não aos cirurgiões-dentistas, diminuindo e limitando a influência das redes sociais fortemente presente no início da graduação ${ }^{9,24}$. Outro ponto fundamental é referente às diversas controvérsias existentes entre as resoluções publicadas, gerando inúmeras dúvidas sobre a legitimidade dos procedimentos envolvidos na Harmonização Orofacial realizada por cirurgiões-dentistas, fato que intensifica a discussão entre profissionais das áreas médica e odontológica e seus respetivos conselhos ${ }^{2,7}$.

\section{CONCLUSÃO}

A maioria dos estudantes do primeiro semestre considera os procedimentos como permitidos, o que diverge das respostas dos graduandos do último semestre, entre os quais a proibição dos procedimentos se mostrou como resultado predominante. Foi possível, também, observar a grande influência das redes sociais e a importância da graduação frente à formação profissional.

\section{ABSTRACT \\ Knowledge of Dentistry undergraduates about Orofacial Harmonization}

The demand for aesthetic and rejuvenating treatments is increasing in society and it is also evident in Dentistry, in which many professionals aim to highlight the beauty of the patient. In this context, many dentists are doing procedures to harmonizing teeth, lips and face as a whole set. This situation needs to be analyzed based in current legislation, also considering the administrative rules and resolutions. The present study aimed to verify the knowledge of undergraduate students in Dentistry from the first and the last semester of the graduation, through a questionnaire with ten questions about the ethical and legal aspects of procedures that integrate the Orofacial Harmonization, as well as the sources of information about the issue. It was possible to observe that in the first semester, most of the answers include the permissibility of the procedures, fact that differs from the answers of the students from the last semester, because they consider as prohibited procedures for dentists. Thus, it is evidenced the importance of the Forensic Dentistry in formation of a critical and reflexive profile of the students during the undergraduate courses, given the divergence between the understanding of participants from the first and the last semester about the permissibility of the procedures.

Descriptors: Ethics, Dental. Esthetics. Legislation, Dental. Forensic Dentistry.

\section{REFERÊNCIAS}

1. Cavalcanti AN, Azevedo JF, Mathias P. Harmonização Orofacial: a Odontologia além do sorriso. Rev Bahiana Odontol. 2017; 8(2): 35-6.

2. Rosa KSS, Rodrigues LS, Giansante JRL. Aspectos éticos e legais do uso de toxina botulínica e preenchedores faciais na Odontologia [dissertação]. Aracajú (SE): Universidade Tiradentes; 2017.

3. Narvai PC. Recursos humanos para promoção de saúde bucal: um olhar no início do século XXI. Promoção de saúde bucal: paradigma, ciência, humanização. 2003; 3: 475-94.

4. Jesus RF, Vieira PGM, Vieira EAC. O uso da Toxina Botulínica e materiais 
preenchedores na Harmonização Facial. VIII

Encontro de Iniciação Científica da Universidade Vale do Rio Verde. 2016; Belo Horizonte, MG.

5. Reis AB, Moreira MJF, Vianna ACF. Prontuário odontológico na harmonização orofacial e o risco iminente de processo cível. Anais da Jornada de Odontologia da Faculdade Patos de Minas. 2019; Patos de Minas, MG.

6. Bichectomia: o que é? Quais os prós e os contras? [Internet]. APCD Jornal. 2016. [Acesso em 07 de fevereiro de 2019]. Disponível em: http://www.apcdsaude.org.br/detNot.asp?id=1644\&moda $=0$ 53\&contexto $=\&$ area $=015 \&$ evento.

7. Jacometti V, Coltri MV, Santos TS, Silva RHA. Procedimento de bichectomia: uma discussão sobre os aspectos éticos e legais em Odontologia. Rev Bras Cir Plast. 2017; 32(4): 616-23.

8. Pereira JGD, Recalde TSF, Costa PB, Jacometti V, Magalhães LV, Silva RHA da. Forensic odontology education: from undergraduate to $\mathrm{PhD}$ - a Brazilian experience. J Forensic Odontostomatol. 2017; 2(35): 149-56.

9. Oliveira CML, Bezerra ESM, Lobato IH, Nobre RM, Machado SM, Barroso RF. Processos movidos contra cirurgiõesdentistas no Conselho Regional de Odontologia - seção Pará - nos últimos sete anos. Saúde, Ética \& Justiça. 2010; 15(2): 46-52.

10. Amorim KPC, Alves MSCF, Germano RM, Costa ICC. A construção do saber em Odontologia: A produção científica detrês periódicos brasileiros de 1990 a 2004. Interface Comun Saúde, Educ. 2007; 11(21): 9-23.

11. Brasil. Resolução CNE/CES no 3, de 19 de fevereiro de 2002. Institui Diretrizes
Curriculares Nacionais do Curso de Graduação em Odontologia. Conselho Nacional de Educação. [Acesso em 07 de fevereiro de 2019]. Disponível em: http://portal.mec.gov.br/cne/arquivos/pdf/C ES032002.pdf.

12. Brasil. Resolução CNS no 466, de 12 de dezembro de 2012. Conselho Nacional de Saúde. [Acesso em 07 de fevereiro de 2019]. Dispoínvel em: http://bvsms.saude.gov. br/bvs/saudelegis/cns/2013/res0466_12_12 2012.html.

13. Conselho Federal de Odontologia. Resolução CFO-198, de 29 de janeiro de 2019. Reconhece a Harmonização Orofacial como especialidade odontológica, e dá outras providências. [Acesso em 13 de março de 2019]. Disponível em: http://cfo.org.br/ website/wp-content/uploads/2019/01/Resolu \%C3\%A7\%C3\%A3o-CFO-198-2019.pdf.

14. Conselho Federal de Odontologia. Resolução CFO-100, de 18 de março de 2010. Baixa normas para a prática da Cirurgia e Traumatologia Bucomaxilofaciais, por cirurgiões-dentistas. [Acesso em 13 de março de 2019]. Disponível em: http://www.crosp.org.br/ uploads/paginas/332908a12e5f1cca55dc48 230fd75e55.pdf.

15. Conselho Federal de Odontologia. Resolução CFO-112, de 02 de setembro de 2011. Baixa normas sobre a utilização do uso da toxina botulínica e ácido hialurônico. [Acesso em 13 de março de 2019]. Disponível em: http://cromg.org.br/ arquivos/Resolucao\%20CFO112-2011.pdf.

16. Conselho Federal de Odontologia. Resolução CFO-145, de 27 de março de 2014. Altera redação de artigos da Resolução CFO-112/2011. [Acesso em 13 de março de 2019]. Disponível em: http://www.croma.org.br/normas/F/federal 
2014_104.pdf.

17. Conselho Federal de Odontologia. Resolução CFO-146, de 16 de abril de 2014. Altera o artigo $2^{\circ}$ da Resolução CFO112/2011. [Acesso em 13 de março de 2019]. Disponível em: http://www.croma. org.br/normas/F/federal_2014_105.pdf.

18. Conselho Federal de Odontologia. Resolução CFO-176, de 06 de setembro de 2016. Revoga as Resoluções CFO112/2011, 145/2014 e 146/2014, referentes à utilização da toxina botulínica e preenchedores faciais, e aprova outra em substituição. [Acesso em 13 de março de 2019]. Disponível em: www.cromt.org.br/ legislacao/download/19.

19. Brasil. Lei n ${ }^{\circ} 5.081$, de 24 de agosto de 1966. Regula o Exercício da Odontologia. [Acesso em 13 de março de 2019]. Disponível em: http://www.planalto.gov.br/ccivil_03/leis/L 5081.htm.

20. Conselho Federal de Odontologia. Resolução CFO-63/2012. Consolidação das Normas para Procedimentos nos Conselhos de Odontologia. [Acesso em 13 de março de 2019]. Disponível em: http://transparencia.cfo. org.br/wp-content/uploads/2018/03/consolida cao.pdf.

21. Justiça suspende a Resolução CFO176/2016: está vedada a utilização da toxina botulínica e dos preenchedores faciais por cirurgiões-dentistas, para fins exclusivamente estéticos [Internet]. CROMG. 2017. [Acesso em 13 de março de 2019]. Disponível em: http://www.crogo. org.br/index.php/noticias/1060-justicasuspende-a-resolucao-cfo-176-2016-estavedada-a-utilizacao-da-toxina-botulinica-edos-preenchedores-facias-por-cirurgioesdentistas-para-fins-exclusivamenteesteticos.

22. Nota de esclarecimento: Resolução $n^{\circ}$
176/2016 volta a ter validade do território nacional [Internet]. ABOL. 2018. [Acesso em 13 de março de 2019]. Disponível em: https://contatoabol.wixsite.com/abol/singlepost/2018/11/02/Nota-de-esclarecimentoResolu\%C3\%A7\%C3\%A3o-n\%C2\%BA1762016-volta-a-ter-validade-doterrit\%C3\%B3rio-nacional.

23. Lino-Junior HL, Gabriel M, Daruge-Junior E, Silva RHA. Ensino de Odontologia Legal no Brasil: um convite à reflexão. Rev ABENO. 2015; 15(2): 38-46.

24. Santos VLC, Santos JE. As redes sociais digitais e sua influência na sociedade e educação contemporâneas. HOLOS. 2014; 6: 307-28.

25. Martorell LB, Nascimento WF, Prado MM, Silva RF, Mendes SDSC. O uso de imagens em redes sociais e o respeito ao paciente odontológico. J Health Sci. 2016; 18(2): 104-10.

26. Henry RK, Molnar A, Henry JC. A survey of US Dental Practices' use of Social Media. JCDP. 2012; 13(2): 137-41.

27. Miranda GE, Radicchi R, Júnior ED. Análise de websites de cirurgiões-dentistas quanto aos aspectos éticos e legais relativos à publicidade e propaganda. Rev Bras Odontol. 2013; 70(1): 80-4.

28. Spin MD. Demandas Civis em Odontologia e sua estrita intimidade com a Perícia: a importância do laudo pericial para a composição da sentença [dissertação]. Bauru (SP): Universidade de São Paulo; 2016.

\section{Correspondência para:}

Ricardo Henrique Alves da Silva e-mail: ricardohenrique@usp.br Av. do Café, s/n - Campus da USP Ribeirão Preto 14040-904 Ribeirão Preto/SP 